\title{
Evaluating Collection Parameters for Mobile Lidar Surveys in Vegetated Beach-Dune Settings
} US Army Corps of Engineers

by lan Conery, Nicholas Cohn, Nicholas Spore, Katherine Brodie

PURPOSE: The goal of this Coastal and Hydraulics Engineering Technical Note (CHETN) is to compare collection parameters and gridding techniques for mobile lidar surveys of beach-dune systems in the northern Outer Banks, NC.

INTRODUCTION: Coastal foredunes act as flood prevention features and are increasingly being incorporated into federal beach nourishment projects. Dune dynamics can vary over short spatial scales resulting from the aggregation of geological, oceanographic, meteorological, and ecological factors (e.g., Cohn et al. 2019; Schwartz et al. 2019; Zarnetske et al. 2012), limiting an understanding of how to optimize dune implementation on US Army Corps of Engineers (USACE) erosion and flood damage reduction projects. Decoupling these competing biotic and abiotic factors on dune evolution remains challenging, in part due to a sparsity of high-resolution data suitable for understanding dune eco-morphodynamics.

Mobile terrestrial lidar (MTL), airborne lidar, and unmanned aerial systems (UAS)-based structure from motion (SfM) are data collection platforms that are all capable of providing high-resolution topographic data that can inform an understanding of three-dimensional (3D) dune evolution. All three measurement platforms can be rapidly mobilized, have the capability to cover large stretches of coast, and can provide dense point clouds of coastal topography. Yet each system also has drawbacks that potentially limit its utility for specific coastal monitoring or research efforts. For example, specialized personnel and equipment associated with airborne lidar makes it cost prohibitive for many frequent regional applications and UAS SfM methods may not sufficiently penetrate vegetation resulting in potential data quality issues for developing digital terrain models in densely vegetated dunes. Since MTL is typically collected via mobile platforms driven on the dry sand beach, these MTL systems typically cannot collect data past the foredune crest due to line-of-sight limitations. Despite some limitations of these technologies for specific coastal applications, they all serve as a potential means to fill these critical knowledge gaps on coastal dune dynamics. This effort specifically investigates the capabilities of MTL as a platform for providing accurate and detailed data in coastal regions with vegetated foredunes.

Researchers have recently shown the utility of MTL for measuring bed elevation changes in a variety coastal environments (e.g., Hobbs et al. 2010; Bitenc et al. 2011; Lim et al. 2013). MTL allows for the collection of dense point clouds (typically $100+$ points $/ \mathrm{m}^{2}$ ) ${ }^{*}$ that capture both the bare earth surface and objects above or obscuring the bed surface, such as vegetation, infrastructure, and people. Past research in coastal systems has used MTL to monitor beach nourishment performance (e.g., Pietro et al. 2008), cliff erosion, and regional scale subaerial beach and dune morphology (Donker et al. 2018; Spore et al. 2019). Fixed station (tripod-based)

\footnotetext{
* For a full list of the spelled-out forms of the units of measure used in this document, please refer to US Government Publishing Office Style Manual, 31st ed. (Washington, DC: US Government Publishing Office 2016), 248-52, https://www.govinfo.gov/content/pkg/GPO-STYLEMANUAL-2016/pdf/GPO-STYLEMANUAL-2016.pdf.
} 
terrestrial lidar scanning (FTL) has also widely been utilized for providing valuable new insights on coastal dune dynamics on sub-meter spatial scales and at time scales of months to years (Brodie et al. 2019; Conery et al. 2019; Danchenkov et al. 2019). However, the ability to accurately quantify dune evolution at these same temporal scales utilizing MTL systems, which can cover much larger spatial extents than FTL scanning, would enable significant advancements in the ability to effectively monitor coastal dune evolution at sub-decimeter scale. This advancement has the potential to enhance US Army Corps of Engineers (USACE) coastal monitoring efforts and to provide further scientific advancements in understanding dune morphodynamics.

As MTL is an emerging technology, measurement uncertainties and limitations of platforms are often insufficiently quantified. This paucity of past work complicates interpretation of MTL outputs in coastal landscapes, such as appropriately incorporating measurement errors into estimated volumetric changes of beach-dune systems and for inferring sediment transport processes (e.g., aeolian deposition patterns) from morphology change data. Furthermore, optimal data collection strategies likely vary by survey area of interest and may depend on local geomorphological (e.g., beach slope, dune vs. cliff setting) and ecological (e.g., vegetation type and characteristics) factors. The overarching goal of this technical note is to evaluate different MTL collection and processing parameters (e.g, grid size) for optimal accuracy and operational efficiency based on repeat data collections using the van-based Coastal Lidar and Radar Imaging (CLARIS) MTL system on a beach-dune system in the northern Outer Banks, NC.

FIELD SITE: MTL field testing occurred at the U.S. Army Engineer Research and Development Center, Coastal and Hydraulics Laboratory, Field Research Facility (FRF) which is located in Duck, NC (Figure 1). The FRF is a coastal oceanographic observatory and research facility housed on 176 acres of oceanfront and soundfront land in the Outer Banks barrier islands. Morphology change of the beach and surf zone have been measured on site since the 1970s, and the FRF maintains numerous real-time measurements of waves and currents across the surfzone (see the FRF Data Portal for oceanographic and morphologic data streams: https://frfdataportal.erdc.dren.mil/). The survey area for this MTL assessment spanned approximately $900 \mathrm{~m}$ of dune-backed beach along the oceanside portion of the FRF property.

The beach and dune system at the FRF is representative of the morphology along much of the south-eastern US coastline. The beach at the FRF is characterized as intermediate (Short and Hesp 1982), with an average foreshore slope of approximately 1:12 (Plant and Holman 1997). The foreshore grainsize is bimodal with a median grain size of approximately $0.25 \mathrm{~mm}$ (Stauble 1992). In the 1930s and 1940s, a dune was constructed and planted along the FRF property but has been unmanaged and allowed to naturally evolve since then. The foredunes on the FRF property generally range from approximately 6 to $7 \mathrm{~m}$ in height and are vegetated predominantly with Ammophila breviligulata

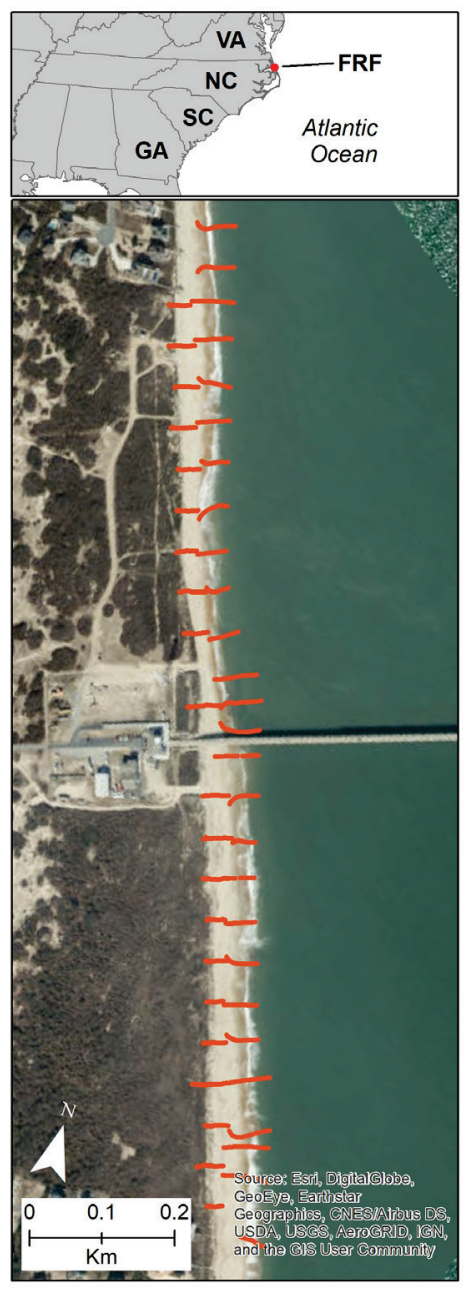

Figure 1. Site map showing location of USACE FRF property (top panel) and location of RTK groundtruth points in red over the CONOPS survey extent (bottom panel). 
(American beachgrass), Uniola paniculata (Sea Oats), and Iva imbricata (dune marsh-elder). Even over sub-meter scales, both the ecological and morphological properties of the dune differ substantially (e.g. Brodie et al. 2019).

\section{METHODS}

MTL Platform. The CLARIS consists of a Riegl VZ2000 lidar scanner (see scanner attributes in Table 1) and an X-band marine radar, which are affixed to a Chevrolet Express 3500 passenger van (center of scanner is $3 \mathrm{~m}$ above wheel base). The CLARIS system also includes an IX-Blue ATLANS-C inertial navigation system (INS) with an integrated inertial measurement unit (IMU), wheel-mounted distance measurement instrument (DMI) and global navigation satellite system (GNSS) antennas (IXBlue 2016) (Table 1). More details regarding the CLARIS instrumentation and capabilities can be found in Spore et al. (2019).

The FRF is equipped with a local GNSS base station used for survey-grade corrections for surveying operations at the facility. Position corrections to the vehicle trajectory are post-processed from the base station and integrated with the CLARIS outputs. Data

\begin{tabular}{|l|l|}
\hline \hline \multicolumn{2}{||l|}{ Table 1. CLARIS instrument attributes. } \\
\hline \hline \multicolumn{2}{|l|}{ RiegI VZ-2000 Specifications } \\
\hline $\begin{array}{l}\text { Laser } \\
\text { wavelength }\end{array}$ & $1550 \mathrm{~nm}$ \\
\hline Range & $2.5-2050 \mathrm{~m}$ \\
\hline $\begin{array}{l}\text { Horiz. angular } \\
\text { stepwidth resolution }\end{array}$ & $0.0024^{\circ}-0.62^{\circ}$ \\
\hline $\begin{array}{l}\text { Vertical angular } \\
\text { stepwidth resolution }\end{array}$ & $0.0015^{\circ}-1.15^{\circ}$ \\
\hline Accuracy & $8 \mathrm{~mm}$ \\
\hline Precision & $5 \mathrm{~mm}$ \\
\hline IX-Blue Specifications \\
\hline $\begin{array}{l}\text { Horizontal (X,Y) position } \\
\text { accuracy }\end{array}$ & $0.020 \mathrm{~m}$ \\
\hline $\begin{array}{l}\text { Vertical (Z) position } \\
\text { accuracy }\end{array}$ & $0.050 \mathrm{~m}$ \\
\hline Roll and pitch accuracy & $0.005^{\circ}$ \\
\hline True Heading accuracy & $0.020^{\circ}$ \\
\hline \hline
\end{tabular}
are natively processed in North Carolina State Plane horizontal coordinates and NAVD88 in the vertical. Data are converted in post-processing to a local horizontal coordinate system with the $\mathrm{x}$ axis aligned with the FRF pier and the y-axis $18^{\circ}$ west of true north.

Data Collection Strategy. This section describes the concept of operations (CONOPS) for the CLARIS data collection for this study. For this work, the INS system was first initialized, and the attitude (roll, pitch and yaw) was calibrated until desired accuracy was achieved based on the instrument's precision $\left(0.02^{\circ}\right)$ by driving and turning CLARIS at various speeds and directions to level the gyroscopes contained within the IMU using the IXBlue software. Once the system was calibrated, CLARIS was driven onto beach, and the lidar system was turned on. Fourteen data collections were conducted using RiAcquire of the same $900 \mathrm{~m}$ of beach and dune within the FRF property (Figure 1). These 14 collections included various combinations of scanning mode (line and radar), driving speed, peak pulse repetition rate, theta resolution, and phi resolution as outlined in Table 2. During the line mode collections, the scanner remained at a fixed angle relative to the shoreline $\left(30^{\circ}\right.$ or $\left.90^{\circ}\right)$ whereas the scanner spun $360^{\circ}$ in radar mode, rotating at different speeds relative to the theta and phi resolutions. Figure 2 schematically shows these linescan and framescan surveying modes. The surveys each took approximately $10 \mathrm{~min}$ to complete and were conducted on August 15, 2019, over the course of $\sim 3$ hours around low tide in order to capture the most exposed beach. The van was driven approximately along the center of the beach, which is typically $\sim 2.5 \mathrm{~m}$ (NAVD88). Weather conditions were clear, and wave conditions were low $\left(\mathrm{H}_{\mathrm{s}} \sim 0.55 \mathrm{~m}\right)$ on the survey day. 


\begin{tabular}{|c|c|c|c|c|c|c|}
\hline$\#$ & $\begin{array}{l}\text { Driving } \\
\text { Speed }(\mathrm{km} / \mathrm{h}) \\
\end{array}$ & Mode & Orientation & $\begin{array}{l}\text { Repetition } \\
\text { Rate }(\mathrm{kHz}) \\
\end{array}$ & $\begin{array}{l}\text { Theta } \\
\left({ }^{\circ}\right)\end{array}$ & $\begin{array}{l}\text { Phi } \\
\left({ }^{\circ}\right)\end{array}$ \\
\hline 1 & 10 & Line & Cross-Shore, $90^{\circ}$ & 1000 & 0.017 & $\mathrm{~N} / \mathrm{A}$ \\
\hline 2 & 10 & Line & Cross-Shore, $90^{\circ}$ & 1000 & 0.057 & $\mathrm{~N} / \mathrm{A}$ \\
\hline 3 & 10 & Line & Cross-Shore, $90^{\circ}$ & 300 & 0.057 & $\mathrm{~N} / \mathrm{A}$ \\
\hline 4 & 10 & Line & Oblique, $30^{\circ}$ & 300 & 0.057 & $\mathrm{~N} / \mathrm{A}$ \\
\hline 5 & 10 & Radar & $360^{\circ}$ & 1000 & 0.05 & 0.7 \\
\hline 6 & 10 & Radar & $360^{\circ}$ & 1000 & 0.057 & 0.35 \\
\hline 7 & 10 & Radar & $360^{\circ}$ & 300 & 0.19 & 0.625 \\
\hline 8 & 20 & Line & Cross-Shore, $90^{\circ}$ & 1000 & 0.017 & $\mathrm{~N} / \mathrm{A}$ \\
\hline 9 & 20 & Line & Cross-Shore, $90^{\circ}$ & 1000 & 0.057 & $\mathrm{~N} / \mathrm{A}$ \\
\hline 10 & 20 & Line & Cross-Shore, $90^{\circ}$ & 300 & 0.057 & $\mathrm{~N} / \mathrm{A}$ \\
\hline 11 & 20 & Line & Oblique, $30^{\circ}$ & 300 & 0.057 & $\mathrm{~N} / \mathrm{A}$ \\
\hline 12 & 20 & Radar & $360^{\circ}$ & 1000 & 0.05 & 0.7 \\
\hline 13 & 20 & Radar & $360^{\circ}$ & 1000 & 0.057 & 0.35 \\
\hline 14 & 20 & Radar & $360^{\circ}$ & 300 & 0.19 & 0.625 \\
\hline
\end{tabular}

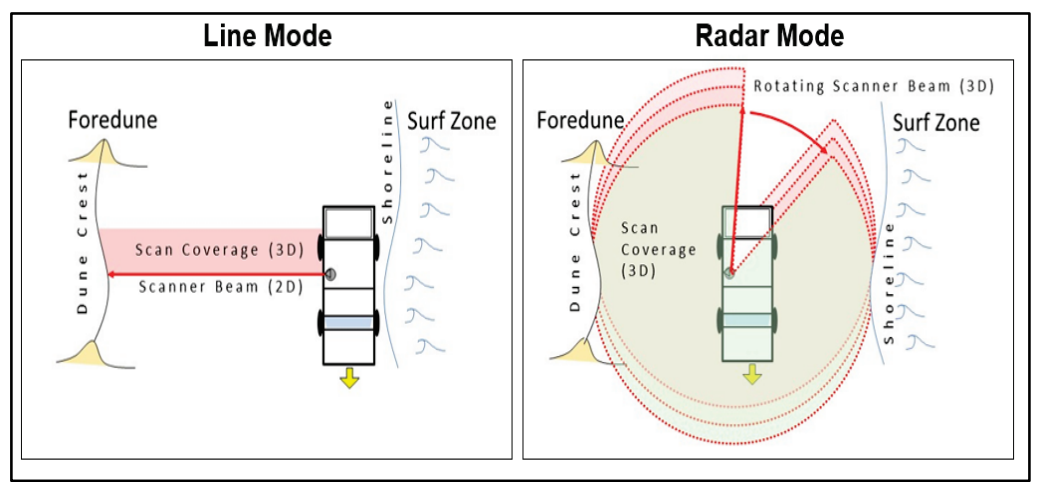

Figure 2. Schematic showing the differences in line vs. radar mode.

At the conclusion of surveying, a boresight alignment survey was conducted to determine the alignment between the INS and the terrestrial lidar scanner. The boresight calibration was conducted within the FRF property where there are numerous planar surfaces (buildings) with varying orientation aspects and the data were boresight corrected following the methods of Rieger et al. (2010).

On the same day of the CLARIS surveys, topographic data of the beach and dunes were collected along cross-shore transects within the FRF using a Trimble R8 real-time kinematic (RTK) backpack system. An advantage of walking-based surveys is that the points always represent the ground surface and are therefore not affected by vegetation. These cross-shore transect data are used to assess CLARIS data collection, particularly within the vegetated dunes of the FRF.

Data Processing. Multiple processing steps are necessary to generate geo-rectified point clouds and produce gridded digital elevation models (DEM). First, GNSS data were post-processed with 
IXBlue's ATLANS Post-Processing Software, which combines data from the local FRF base station with the orientation data recorded by the IMU and DMI, and incorporates a Kalman filter to minimize errors. INS uncertainties were generally consistent across all 14 collection configurations and were within instrument specifications. Raw XYZ point data were directly georeferenced using the position and orientation of the scanner derived from the boresight alignment and the time-varying post-processed INS trajectory.

Next, the shoreline was manually delineated to aid in removal of point returns from the ocean water surface, and point returns from the houses behind the dune were removed. The point clouds were then automatically filtered in Riegl's RiScanPro software using default parameters (Riegl 2018) to classify ground (bare-earth) and non-ground point returns. The ground points were exported from RiScanPro and used to generate DEMs of varying grid cell sizes ( 0.1 to $2.0 \mathrm{~m}$ cells) utilizing the mean function within Matlab. Cells with no data were left empty (interpolation was not used) to help assess the influence of varying CONOPS parameters on gridded DEMs.

Data Analysis. To assess the vertical accuracy and performance of CLARIS, relevant statistics, including point density, mean, minimum, maximum, standard deviation, and variance, were calculated for all CLARIS returns within a $5 \mathrm{~cm}$ distance of each RTK groundtruth point $(\mathrm{n}=$ 1559). Additionally, elevation difference maps between surveys were generated in Matlab. Qualitative evaluation and 3D visualization of point clouds were conducted using QT Modeler.

\section{RESULTS}

Raw (Rectified, Unfiltered) Data. In topographically irregular settings like vegetated dunes, sufficient penetration and return of MTL laser pulses through the vegetation canopy is an important factor in accurately resolving the bed/dune surface. Due to the collection differences of line and radar mode (i.e., a fixed vs. constantly rotating scanner orientation), the final point clouds produced by these CONOPs were expected to have different point distributions and different representations of the bed/dune surface beneath the vegetation. Within line and radar modes, point distribution was also affected by the scan repetition rate and horizontal and vertical angular resolution settings of the scanner.

Figure 3 shows all point returns (ground and non-ground) for each collection along a $10 \mathrm{~m}$ alongshore and $40 \mathrm{~m}$ cross-shore subsection of the field site. In all line scan mode collections, there are notable gaps in data coverage around the $3 \mathrm{~m}$ NAVD88 contour (near cross-shore coordinate 70). This pattern is a result of tire track shadowing along a narrow corridor where lifeguard and FRF vehicles regularly transit. There is more complete coverage of this trafficked zone with deep tire ruts in all of the radar mode collections. There are also spatial gaps in data coverage on the vegetated foredune region ( $>3.5 \mathrm{~m} \mathrm{NAVD} 88, \sim 50-65 \mathrm{~m}$ in cross-shore) for all of the line scan modes. These gaps are largely associated with shadowing by vegetation or morphology on the foredune face. Due to multiple view angles, radar mode produced more spatially complete point clouds when compared with the linescan collect modes, with the exception of Radar 14, which had both the slowest scan repetition rate and coarsest angular and vertical resolution.

A cross-shore profile of all raw data points within $25 \mathrm{~cm}$ of alongshore extent $\mathrm{y}=810 \mathrm{~m}$ and above $\mathrm{z}=3.0 \mathrm{~m}$ NAVD88 are shown in Figure 4. These example data demonstrate how the details of the vegetation properties (e.g., height and location) are resolved differently among the different collection strategies. 


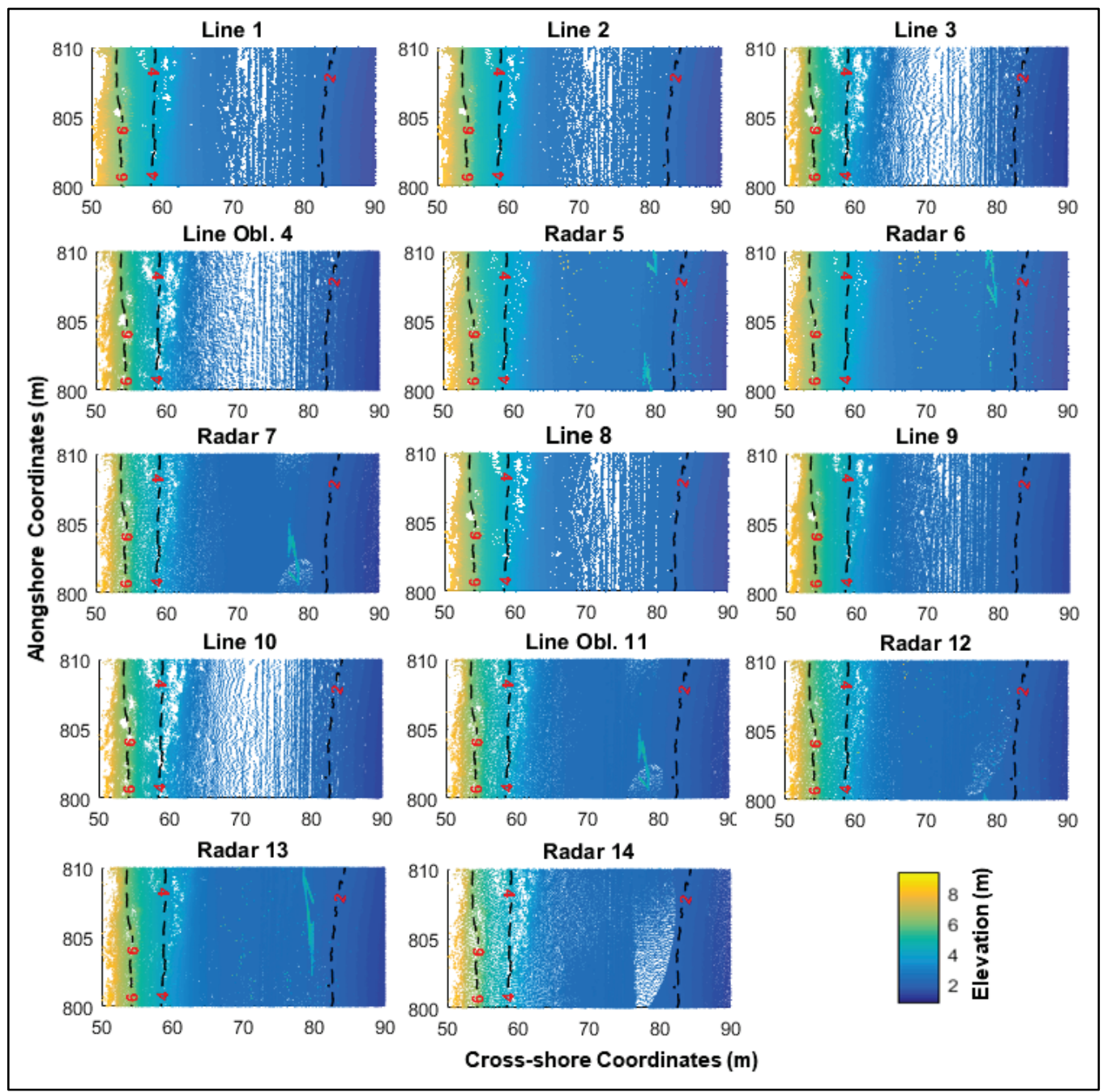

Figure 3. Segments of raw point clouds for the 14 collection types listed in Table 2.

Filtered Data. Automated filtering using default Riegl parameters was used to remove vegetation and other non-ground returns from the lidar point cloud (Riegl 2018). The filtered data from $y=$ $810 \mathrm{~m}$ is compared to the unfiltered cross-shore data at $\mathrm{y}=810 \mathrm{~m}$ in Figure 4 for all 14 collection strategies. Generally the filtered datasets (black dots in Figure 4) are similar between the different collections, especially on the beach (not shown) and the lower portion of the dune ( $3.5 \mathrm{~m} \leq \mathrm{z} \leq 5$ $\mathrm{m})$. However, Figure 4 shows that there are some differences in data continuity in vegetated zones. For example, there are gaps in bed returns (black dots) behind dense dune vegetation (red dots) near $4.5 \mathrm{~m}$ NAVD in Line Oblique 11. Differences are also apparent near the dune crest resulting in a bed elevation estimates of between 6.55 and $6.2 \mathrm{~m}$ NAVD 88 at $\mathrm{x}=53 \mathrm{~m}$. These differences at high parts of the dune likely result from limits to penetration through dense vegetation, reduced point density with distance away from the scanner, and/or limits to accurately resolving bed elevations at near horizontal or upward looking lines of sight. 


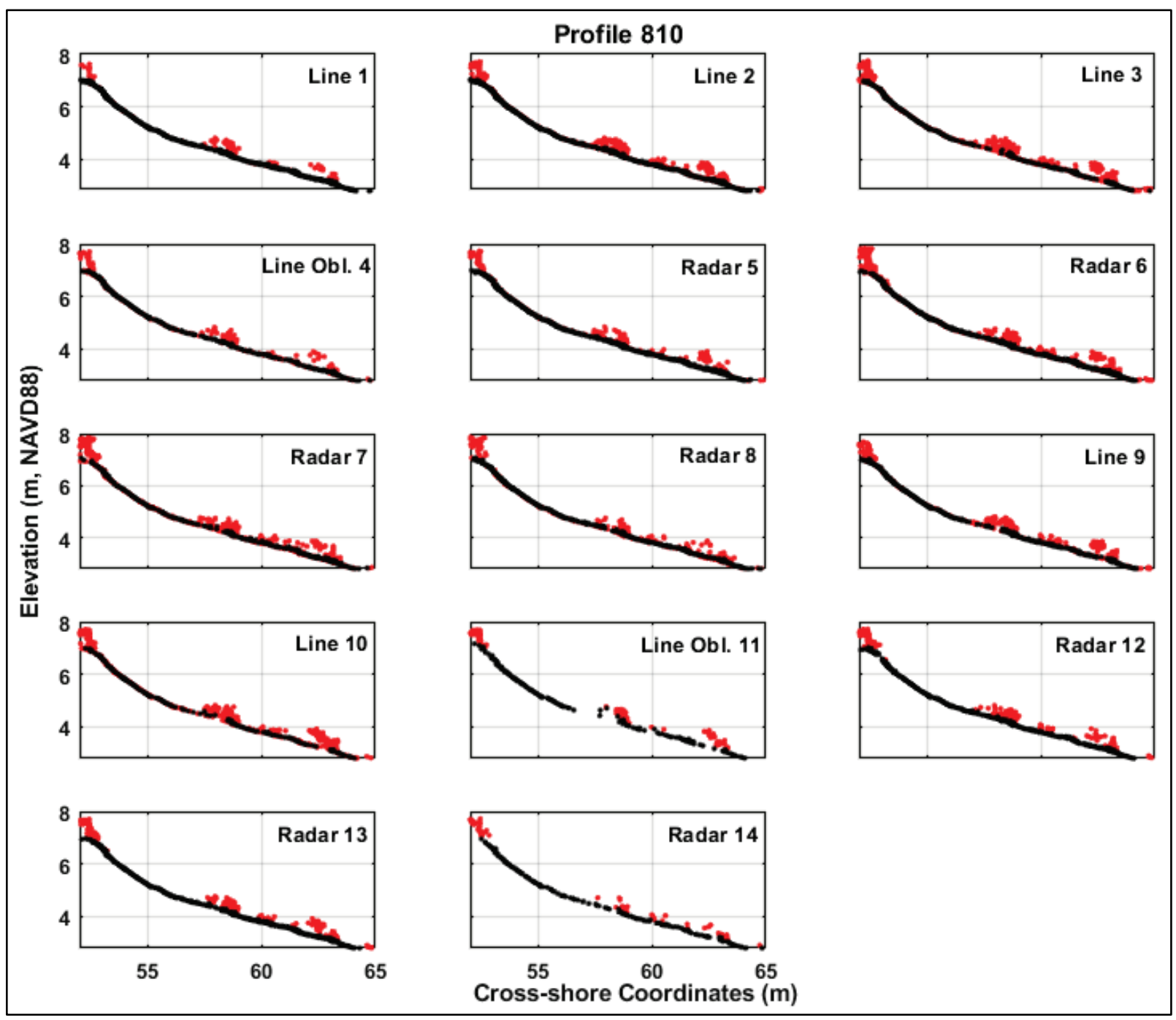

Figure 4. Filtered ground cover (red) and ground (black) data from all CONOPS for $y=810 \mathrm{~m}(+/-5 \mathrm{~cm})$.

To understand the impact of each collection parameter on MTL accuracy and point density, the filtered MTL points are compared to nearby RTK ground truth points. Figure 5 shows the mean point density and mean elevation differences between the points in $5 \mathrm{~cm}$ radii around each RTK ground truth point. Frequency (pulse repetition rate) of the measurements appears to have the strongest control on point density, with higher frequencies yielding higher point densities (Figure 5e). When comparing scans collected at $300 \mathrm{kHz}$, the oblique line mode achieved slightly higher densities over the cross-shore line and radar modes. No consistent trends are apparent when relating point density to driving speed, theta resolution or phi resolution. 


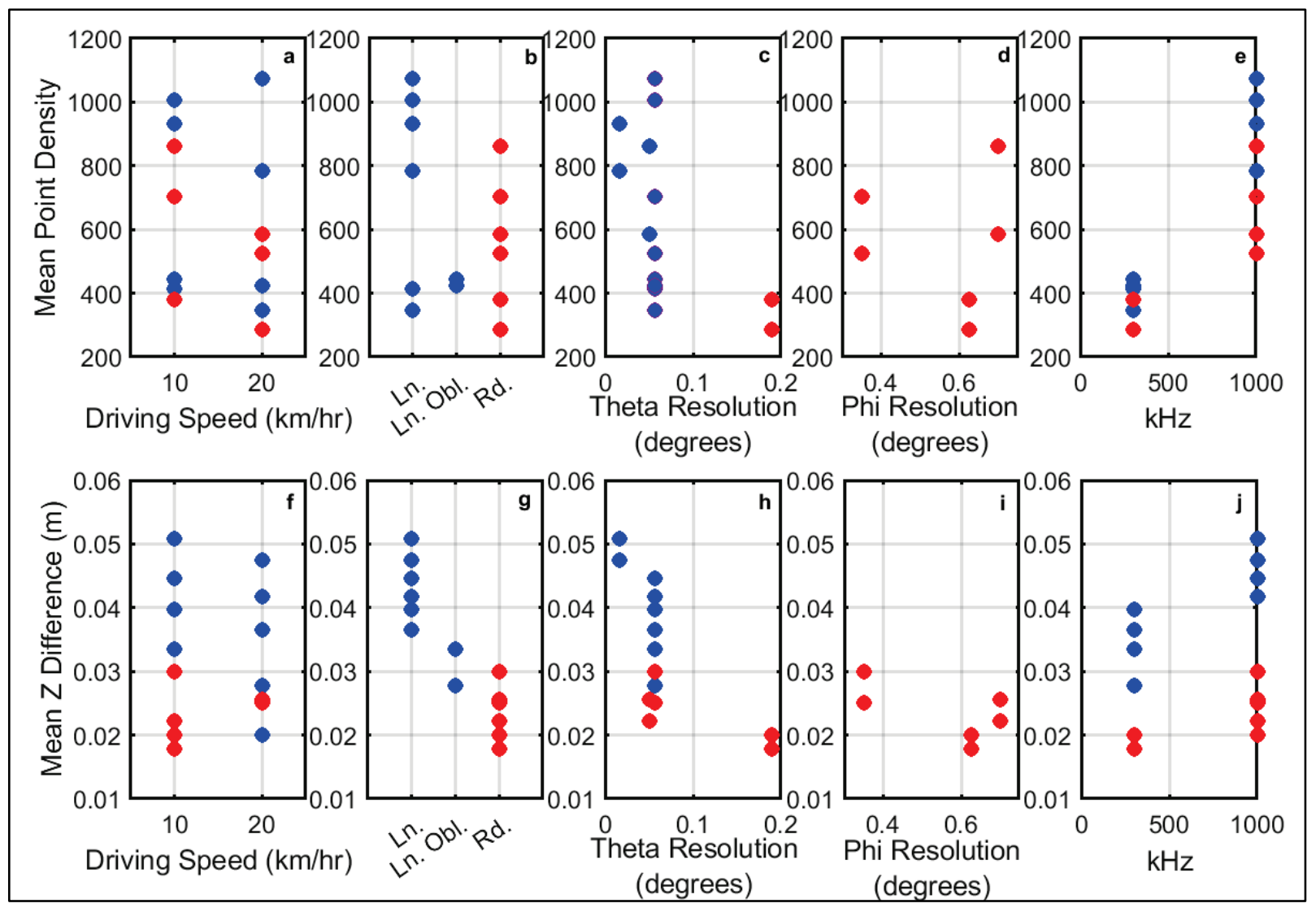

Figure 5. Mean point density (upper panels) and mean elevation difference (lower panels) of the CLARIS data within a $5 \mathrm{~cm}$ radii around RTK groundtruth points $(n=1559)$ relative to line mode (blue) and radar mode (red) collection parameters.

Driving speed, theta resolution, and phi resolution do not appear to have a major influence on mean difference between CLARIS-derived point elevations $(Z)$ and the groundtruth points (Figure 5f-j). In terms of scanner mode, the lowest $Z$ differences were achieved in radar mode, followed by lineoblique and standard line modes. Mean elevation differences among all radar mode scans and the groundtruth were less than $3 \mathrm{~cm}$ whereas mean elevation differences among all line-scan modes and the groundtruth were higher, between 3.5 and $5.2 \mathrm{~cm}$. The data with the smallest elevation differences relative to ground truth were collected at $300 \mathrm{kHz}$ in radar mode. Despite the qualitative observations that data quality was reduced with increased driving speed, there is no clear quantitative support between the MTL and RTK point data to support that there is reduced point density or data quality between driving $10 \mathrm{~km} / \mathrm{hr}$ and $20 \mathrm{~km} / \mathrm{hr}$. The mean standard deviation of points within $5 \mathrm{~cm}$ of the ground truth points were below $0.81 \mathrm{~cm}$ for all of the collected data.

Assuming the backpack-based RTK topographic measurements represent the real bed elevations with no error, which is not the case (e.g., Ruggiero et al. 2005) particularly on steep dune faces, the mean vertical error (bias) of the CLARIS data is lowest for all 14 measurement collections on the lower portion of the beach $(<3 \mathrm{~m})$ as shown in Figure 6 . The mean bias for all elevations below $3 \mathrm{~m}$ is $0.03 \mathrm{~m}$. However, note that for this experiment, $73 \%$ of the total paired CLARIS and RTK groundtruth points for all collections fell below 3 m NAVD88 because of the greater width of beach compared to dune. These biases progressively increase within increasing elevation. Mean $\mathrm{Z}$ 
error increased with higher elevations, particularly those with elevations above $5 \mathrm{~m}$ NAVD88 (Figure 6). The highest Z errors were at points located in the vegetated upper dune and crest ( $>5 \mathrm{~m}$ NAVD88) based on this analysis, where a combination of lack of laser penetration and ineffective filtering produces errant, positively skewed bed elevation points (Figure 6). Additional errors throughout the dune region $(>3 \mathrm{~m}$ NAVD88) could potentially result from RTK measurement errors on steep terrain, fewer RTK and CLARIS points for comparison in this upper dune zone, and/or a range-related bias in the CLARIS system. However, comparison of the CLARIS MTL to fixed control points in previously reported efforts (Spore and Brodie 2017) at the FRF

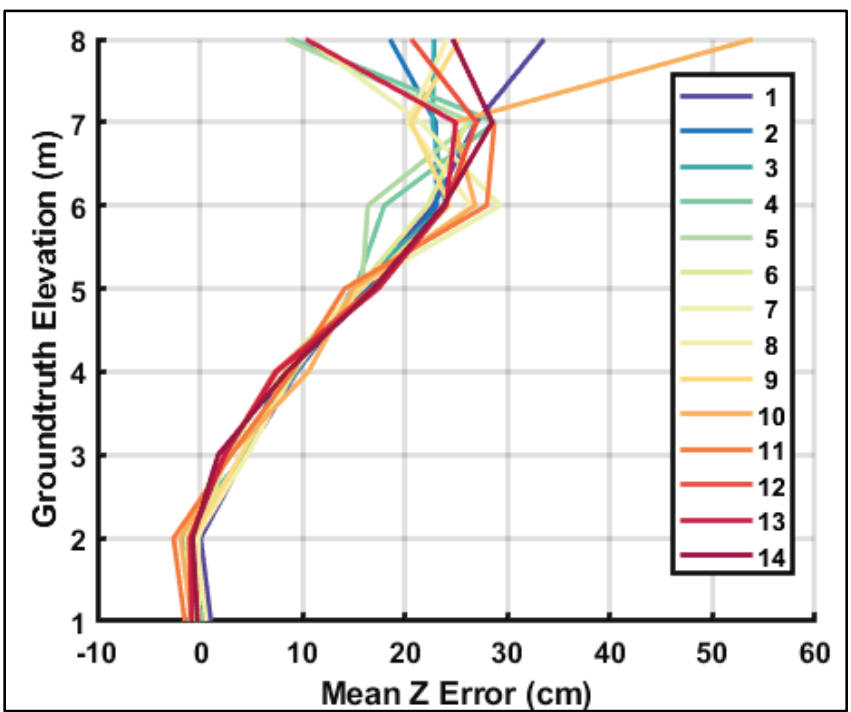

Figure 6. Mean Z error from CLARIS binned by RTK groundtruth elevation for each collection (colors). suggests that range-related biases are unlikely in this case. When omitting values greater than $6 \mathrm{~m}$, mean $\mathrm{Z}$ differences are less than $4 \mathrm{~cm}$ for all 14 data collections and for 6 out of the 14 collections the mean $Z$ difference was less than $2 \mathrm{~cm}$ (data not shown).

Gridded Data. Gridding is typically the last step necessary to generate a DEM, which can be used to quantify elevation change and volumetric analyses. In this work, each of the 14 data collects were

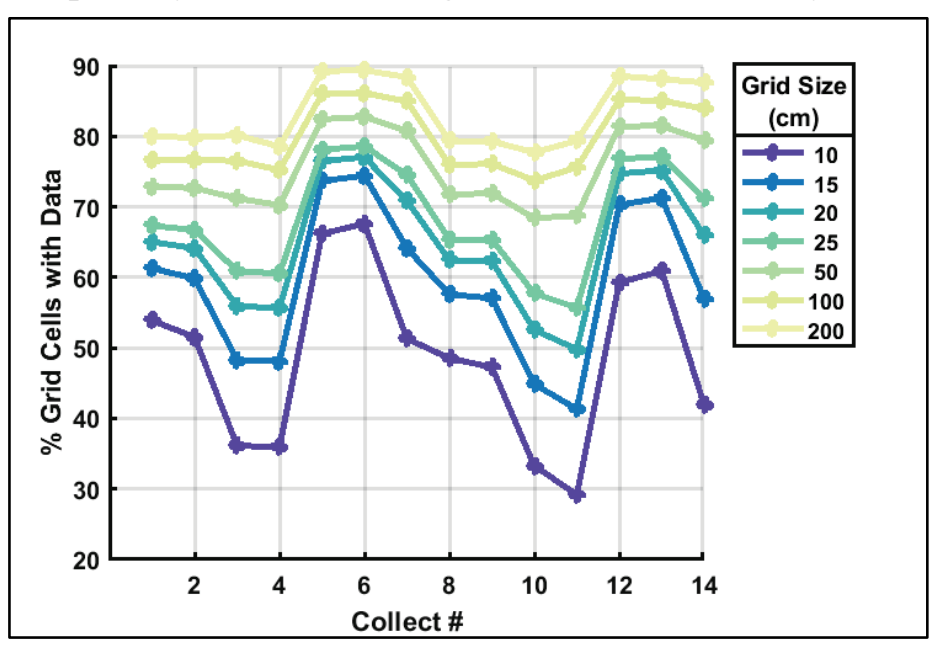

Figure 7. Percent of cells with at least one bed elevation return for each grid size (colors) and collection. gridded onto grid sizes from $10 \mathrm{~cm}$ to $2 \mathrm{~m}$, with elevations determined as the mean elevation of all lidar point returns within that cell. Grid cells with no points within the domain were left empty (e.g., not-anumber or no data value). Figure 7 shows the percentage of grid cells that included at least one point return for each grid size and CONOPS collection, providing an indication of the data density and suitability for further analyses. Smaller grid sizes (i.e., $10 \mathrm{~cm}$ ) had a higher percentage of grid cells with no data (Figure 7). Conversely, grids with a high percentage of cells containing numerous points generally allows for a more accurate gridded surface. However, too large of a grid size will induce significant averaging of the data, which may poorly characterize non-flat (steep or complex) morphology. An example of the influence of grid sizes on the morphology characterization is shown in Figure 8 for data collect 7. Grid cell sizes of $10,15,20$, and $25 \mathrm{~cm}$ produce similar surfaces for this example profile. When the cell size is increased to $50 \mathrm{~cm}$ or larger, the vertical offsets and differences among the gridded profiles become more evident on the dune face and crest. 


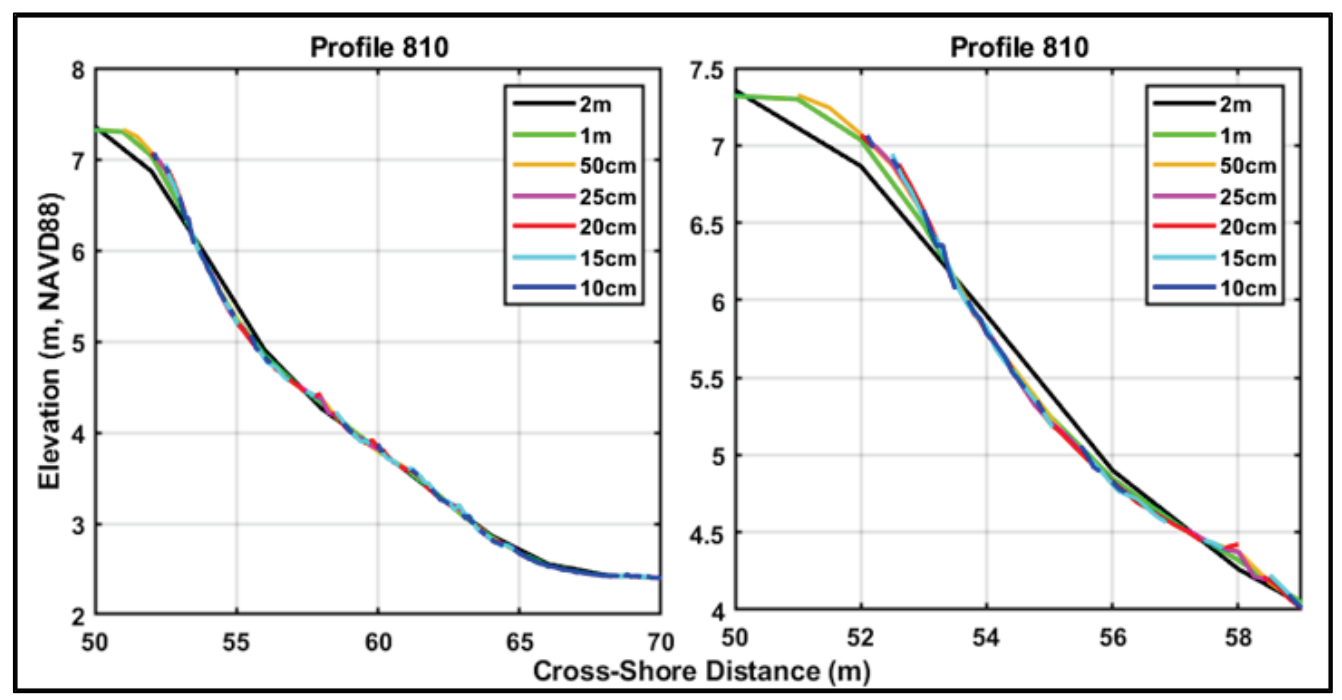

Figure 8. Profile 500 showing the products of different grid sizes.

Figure 9 shows an example of mean Z DEMs generated for all 14 data collects using a $25 \mathrm{~cm}$ grid size, standard deviations for each DEM, and elevation differences relative to data collect 7, which was chosen based on low vertical error and high point density (due to space restrictions not all dataset comparisons are shown). Consistent with the raw and filtered data analysis, vertical differences between the 14 surveys and the representative data collect 7 show minimal differences across the beach but become more apparent midway up the dune face ( 4.5 $\mathrm{m}$, NAVD88). Figure 10 shows elevation differences of collect 3 relative to collect 7 at $100 \mathrm{~cm}$ grid size for the whole survey extent. Figure 10 also highlights the differences in the steepness of the north versus the south dunes.

DISCUSSION AND RECOMMENDATIONS: MTL is a potentially valuable tool that allows for the collection of detailed morphology data on sandy beach-dune systems. Here, various data collection strategies were tested using the CLARIS MTL system at the USACE FRF. While all 14 CONOPS configurations resulted in high resolution and accurate data (i.e., low vertical error), there are pros and cons of each data collection strategy.

For applications to vegetated coastal foredunes over local to regional $(10 \mathrm{~s} \mathrm{~km})$ scales, as is typically completed at the FRF as part of ongoing post-storm assessments, there are specific advantages to collecting data in radar mode. There are generally fewer spatial gaps in the datasets associated with radar mode that limits shadowing behind vegetation and other obstructions. This improves the ability to accurately resolve the bed/dune surface, reducing the potential for elevation errors, and therefore increases data quality for process-oriented or volumetric studies. Line mode, while advantageous in some cases (e.g., steep slopes such as cliffs) (Young et al. 2020), suffers from a lack of data behind obstructions (e.g., vegetation, tire tracks) and may require two passes of the beach (near the dune and lower on the beach) to achieve the desired point penetration and distribution on vegetated dune faces. This CONOPS would effectively double the survey time (or reduce the alongshore extent by half) and produce similar quality data when compared with radar mode. 


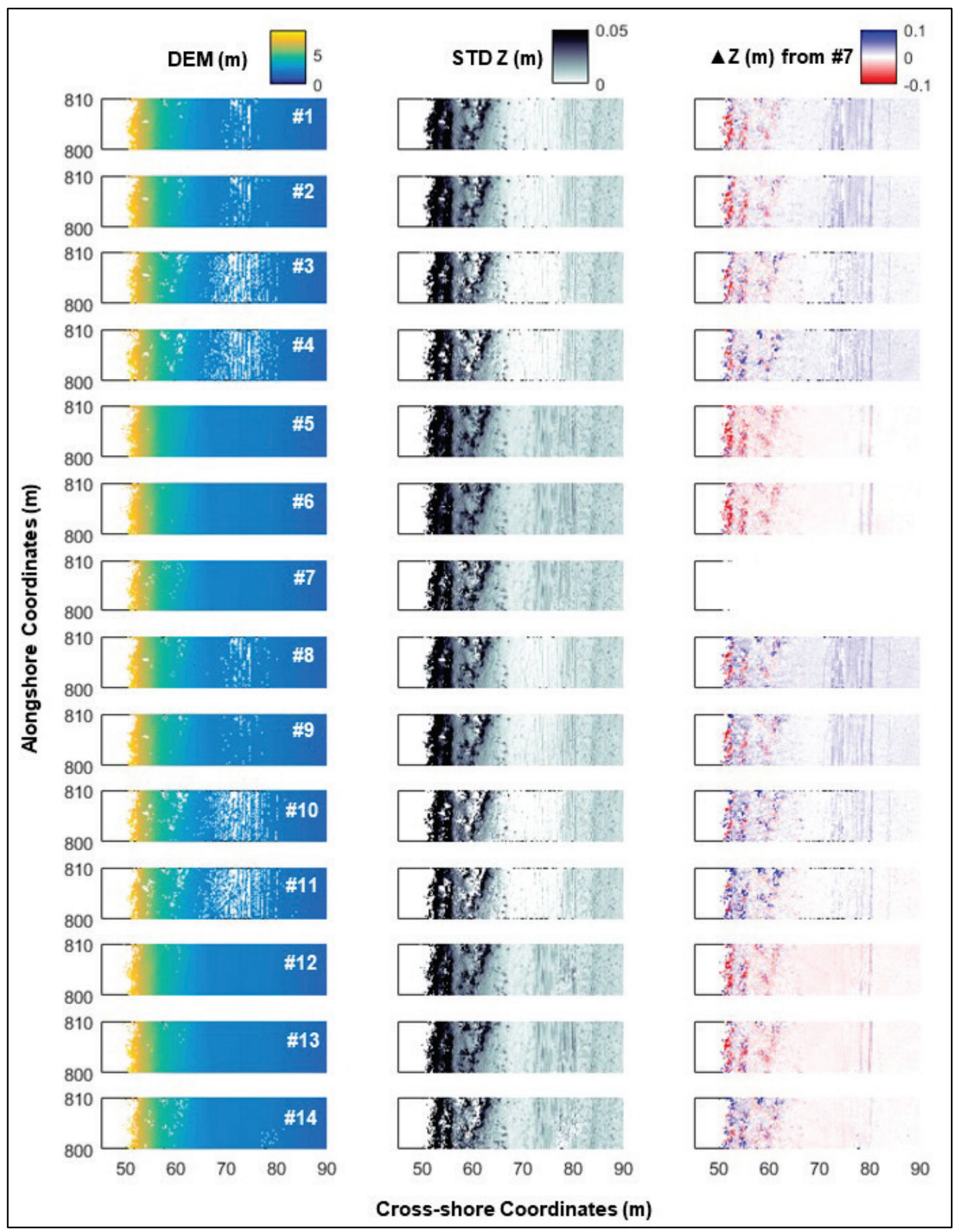

Figure 9. Mean Z DEM (column 1) for each collection number (white text), standard deviations for each DEM (column 2) and Z differences from collection \#7 (column 3). 


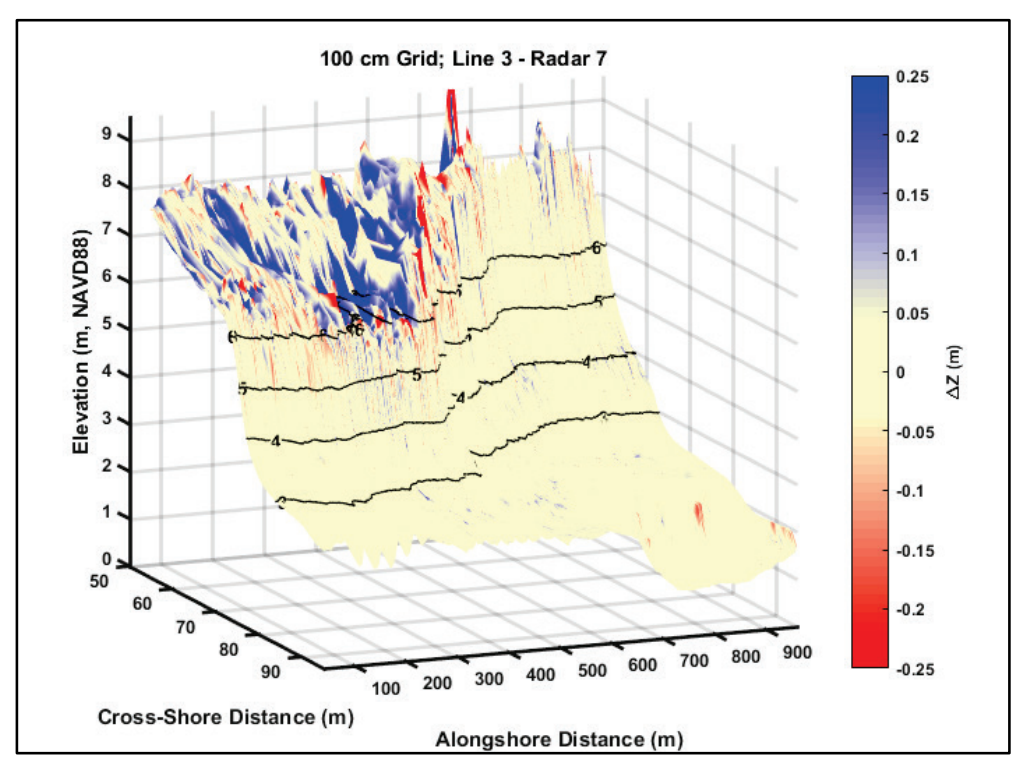

Figure 10. Elevation differences (colors) across the survey extent between collect \#3 and collect \#7 using a $100 \mathrm{~cm}$ grid.
Although data at the control points do not indicate any clear trends in terms of a relationship between driving speed and data quality, the limited RTK points do not capture the full three-dimensionality of the beach-dune morphology. Analysis of the gridded products generally indicates that a more spatially complete data product is achieved for lower driving speed and a faster laser pulse repetition rate. However, this mode of operation also produces more overall returns in larger data files, which may pose challenges for data processing and storage. In this particular application, theta and phi appear to have minimal impacts on accuracy. Gridding parameter choices have a significant impact on the final DEM, which potentially outweighs the aforementioned differences in instrument parameters. Moving forward, CLARIS surveys will most often use parameters of collection $7\left(10 \mathrm{~km} / \mathrm{h}\right.$, radar $360^{\circ}, 300 \mathrm{kHz}, 0.19$ theta, 0.625 phi) (Table 2) using an average gridding method with a $25 \mathrm{~cm}$ or smaller cell size, based on the outcome of this work.

FUTURE WORK: The plan is to test platform repeatability to better quantify the magnitude of potential instrumentation errors by repeating the same collection strategy survey configuration numerous times. In addition, there will be continuing exploration of other filtering techniques within and outside of Riegl (e.g., PDAL, LASTOOLS, cloth filtering, etc.) to improve removal of vegetation from DEMs and investigate elevation related bias (Figure 6). Last, as part of ongoing work, there will be an integration of the LadyBug5 camera system on to the CLARIS, which will allow for co-located RGB information with the XYZ data. This additional data stream can potentially improve vegetation/structure point classification and enable improved DEM accuracy in vegetated regions.

ADDITIONAL INFORMATION: This CHETN was prepared by Dr. Ian Conery, Dr. Nicholas Cohn, Nicholas Spore, and Dr. Katherine Brodie of the US Army Engineer Research and Development Center, Coastal and Hydraulics Laboratory, Coastal Observation and Analysis Branch as part of the "Resilience of Coastal Dunes" work unit funded under the USACE Flood and Coastal Systems (F\&CS) Research and Development (R\&D) Program. Relevant Statements of Need that motivated this work include (1) 2014-N-10 Update of Engineering Guidance for the Development and Maintenance of Coastal Dune Systems, (2) 2017-N-72 Improved Simulation of Dune Morphological Response at Short \& Long Time-scales, and (3) 2020-F-1539 Improved Capabilities for Quantifying Coastal Dune Evolution and Resilience. This work also leveraged the use of the CLARIS MTL system, which has was developed through the Remote Sensing work unit of the USACE Coastal Field Data Collection (CFDC) R\&D Program. Questions pertaining to this CHETN may be directed to Ian Conery 
(Ian.W.Conery@usace.army.mil); the USACE F\&CS Program Manager is Dr. Brandon Boyd (Brandon.M.Boyd@,usace.army.mil); and the CFDC Program Manager is Dr. Jeffrey P. Waters (Jeffrey.P.Waters@usace.army.mil).

This ERDC/CHL CHETN-II-58 should be cited as follows:

Conery, I., N. Cohn, N. Spore, and K. Brodie. 2020. Evaluating Collection Parameters for Mobile Lidar Surveys in Vegetated Beach-Dune Settings. ERDC/CHL CHETN-II-58. Vicksburg, MS: US Army Engineer Research and Development Center. http://dx.doi.org/10.21079/11681/37759

\section{REFERENCES}

Bitenc, M., R. Lindenbergh, K. Khoshelham, V. Waarden, and A. Pieter. 2011. "Evaluation of a LiDAR Land-Based Mobile Mapping System for Monitoring Sandy Coasts." Remote Sensing 3(7): 1472-1491.

Brodie, K., I. Conery, N. Cohn, N. Spore, and M. Palmsten. 2019. "Spatial Variability of Coastal Foredune Evolution, Part A: Timescales of Months to Years." Journal of Marine Science and Engineering 7(5): 124.

Cohn, N., B. M. Hoonhout, E. B. Goldstein, S. De Vries, L. J. Moore, O. Durán Vinent, and P. Ruggiero. 2019. "Exploring Marine and Aeolian Controls on Coastal Foredune Growth Using a Coupled Numerical Model." Journal of Marine Science and Engineering 7(1): 13.

Conery, I., K. Brodie, N. Spore, and J. Walsh. 2019. "Terrestrial Lidar Monitoring of Coastal Foredune Evolution in Managed and Unmanaged Systems.” Earth Surface Processes and Landforms 45(4): 877-892.

Danchenkov, A., N. Belov, and Z. Stont, 2019. "Using the Terrestrial Laser Scanning Technique for Aeolian Transport Assessment in the Coastal Zone in Seasonal Scale." Estuarine Coastal and Shelf Science 223: 105114. doi: $\underline{10.1016 / j . e c s s .2019 .04 .044}$

Donker, J., M. van Maarseveen, and G. Russink. 2018. "Spatio-Temporal Variations in Foredune Dynamics Determined with Mobile Laser Scanning.” Journal of Marine Science and Engineering 6: 126. doi:10.3390/jmse6040126

Hobbs, P. R. N., A. Gibson, L. Jones, C. Pennington, G. Jenkins, S. Pearson, and K. Freeborough. 2010. "Monitoring Coastal Change Using Terrestrial LiDAR." Geological Society, London, Special Publications 345(1): 117-127.

IXBlue. 2016. ATLANS-C Mobile Mapping Position and Orientation Solution.

Lim, S., C. A. Thatcher, J. C. Brock, D. R. Kimbrow, J. J. Danielson, and B. J. Reynolds. 2013. “Accuracy Assessment of a Mobile Terrestrial Lidar Survey at Padre Island National Seashore." International Journal of Remote Sensing 34(18): 6355-6366.

Pietro, L. S., M. A. O'Neal, and J. A. Puleo. 2008. "Developing Terrestrial-LIDAR-Based Digital Elevation Models for Monitoring Beach Nourishment Performance.” Journal of Coastal Research 24(6(246)): 1555-1564.

Plant, N. G., and R. A. Holman. "Intertidal Beach Profile Estimation Using Video Images.” Mar. Geol. 1997 140(12): $1-24$.

Rieger, P., N. Studnicka, M. Pfennigbauer, and G. Zach. 2010. "Boresight Alignment Method for Mobile Laser Scanning Systems." Journal of Applied Geodesy 4(1): 13-21. 
Riegl Laser Measurement Systems. 2018. Riegl RiProcess User Manual. Version 1.8.5.

Ruggiero, P., G. M. Kaminsky, G. Gelfenbaum, and B. Voigt. 2005. Seasonal to Interannual Morphodynamics along a High-Energy Dissipative Littoral Cell. Journal of Coastal Research 2005(213): 553-578.

Schwarz, C., J. Brinkkemper, and G. Ruessink. 2019. "Feedbacks between Biotic and Abiotic Processes Governing the Development of Foredune Blowouts: A Review. Journal of Marine Science and Engineering 7(1): 2.

Short, A. D., and P. A. Hesp. 1982. "Wave, Beach and Dune Interactions in Southeastern Australia." Marine Geology 48(3-4): 259-284.

Spore, N., and K. Brodie. 2017. Collection, Processing and Accuracy of Mobile Terrestrial Lidar Survey Data in the Coastal Environment. ERDC/CHL TR-17-5. Vicksburg, MS: US Army Engineer Research and Development Center.

Spore, N., A. Renaud, I. Conery, and K. Brodie. 2019. Coastal Lidar and Radar Imaging System (CLARIS) Lidar Data Report 2011-2017. ERDC/CHL SR-19-4. Vicksburg, MS: US Army Engineer Research and Development Center.

Stauble, D. 1992. Long-Term Profile and Sediment Morphodynamics: Field Research Facility Case History. Technical Report CERC-92-7. Vicksburg, MS: US Army Waterways Experiment Station, Coastal Engineering Research Center.

Young, A., H. Matsumoto, B. Ludka, W. O’Reilly, M. Merrifield, and R. Guza, 2020. "Interactions between Waves, Beaches and Coastal Cliffs." American Geophysical Union, Ocean Sciences 2020, San Diego, CA meeting abstracts. https://agu.confex.com/agu/osm20/preliminaryview.cgi/Paper655082.html

Zarnetske, P. L., S. D. Hacker, E. W. Seabloom, P. Ruggiero, J. R. Killian, T. B. Maddux, and D. Cox. 2012. "Biophysical Feedback Mediates Effects of Invasive Grasses on Coastal Dune Shape." Ecology 93(6): 14391450 .

NOTE: The contents of this technical note are not to be used for advertising, publication, or promotional purposes. Citation of trade names does not constitute an official endorsement or approval of the use of such products. 